Media Informatika, Vol. 4, No. 1, Juni 2006, 67-79

ISSN: 0854-4743

\title{
SISTEM OTENTIKASI, OTORISASI, DAN PELAPORAN KONEKSI USER PADA JARINGAN WIRELESS MENGGUNAKAN CHILLISPOT DAN SERVER RADIUS
}

\author{
Gesit Singgih Febyatmoko, Taufiq Hidayat, Mukhammad Andri S. \\ Jurusan Teknik Informatika, Fakultas Teknologi Industri, Universitas Islam Indonesia \\ Jl. Kaliurang Km. 14 Yogyakarta 55501 \\ Telp. (0274) 895287 ext. 122, Faks. (0274) 895007ext. 148 \\ E-mail: taufighid@fti.uii.ac.id, andri@fti.uii.ac.id
}

\begin{abstract}
ABSTRAK
Sistem otentikasi, otorisasi, dan pelaporan koneksi user pada jaringan wireless dalam penelitian ini meliputi tiga bagian. Bagian yang pertama adalah membangun server UAM (Universal Access Method) dengan chillispot. Kedua adalah konfigurasi server Radius menggunakan software Freeradius. Ketiga adalah membangun aplikasi Sistem Administrasi Hotspot berbasis web menggunakan bahasa pemrograman PHP yang memberikan abstraksi pembangun antarmuka dan pengaksesan basis data menjadi lebih mudah.

Studi kasus diimplementasikan pada jaringan Fakultas Teknik Industri UII dan juga diterapkan pada NOC UIINET (percobaan). Setelah dilakukan pengujian terhadap sistem ini, terbukti bahwa level keamanan WLAN dan pembagian akses layanan dapat menjadi lebih baik. Penggunaan layanan jaringan juga dapat dimonitor oleh administrator melalui aplikasi berbasis web.
\end{abstract}

Kata kunci: Captive Portal, Chillispot, Hotspot, PHP, Radius

\section{PENDAHULUAN}

\subsection{Latar Belakang}

Sebuah institusi yang besar terutama institusi yang tulang punggung eksistensinya menggunakan teknologi informasi membutuhkan penanganan yang baik agar sistem informasi yang ada dapat berjalan dengan optimal. Banyak faktor yang mempengaruhi keoptimalan kinerja sistem informasi, salah satu yang terpenting adalah keamanan sistem.

Jaringan komputer nirkabel atau disebut WLAN (Wireless Area Network) adalah salah satu teknologi yang saat ini sudah digunakan secara luas di berbagai institusi. Selain banyaknya keuntungan dengan memakai teknologi jaringan komputer nirkabel, terdapat juga kekurangan yaitu keamanan dan pembatasan hak akses yang sulit. Isu keamanan dalam penerapan teknologi jaringan komputer 
nirkabel menjadi rawan dikarenakan mekanisme enkripsi (WEP) yang mempunyai banyak kelemahan.

Selain isu keamanan, praktek bisnis yang mengandalkan penyewaan akses WLAN (hotspot) juga membutuhkan sebuah sistem yang mampu mengakomodasi kebutuhan untuk mengelola user, semisal pada kasus, yang bisa mengakses internet adalah user yang terdaftar sebagai member.

\subsection{Rumusan Masalah}

Berdasarkan latar belakang yang telah disebutkan diatas maka dapat ditarik rumusan masalah sebagai berikut: bagaimana menerapkan mekanisme keamanan yang handal dalam WLAN?

\subsection{Batasan Masalah}

Untuk menghindari meluasnya materi yang dibahas pada penelitian ini, maka diberikan batasan masalah sebagai berikut:

1. Mekanisme keamanan pada WLAN menggunakan metode dengan otentikasi, otorisasi dan pelaporan aktifitas koneksi yang dilakukan user.

2. Administrasi terpusat untuk mengelola sistem.

3. Sistem menggunakan metode tiket dan pelanggan untuk merepresentasikan user.

4. Tidak semua user diijinkan menggunakan layanan WLAN, hanya user yang terdaftar (dikenali oleh sistem) yang diijinkan oleh sistem.

\subsection{Tujuan Penelitian}

Tujuan akhir yang akan dicapai dalam penelitian ini adalah untuk membangun sistem terintegrasi yang mengakomodasi kebutuhan administrator jaringan dalam mengelola layanan WLAN dan meningkatkan keamanan jaringan dengan mekanisme otentikasi, otorisasi, dan pelaporan aktifitas koneksi yang dilakukan user.

\section{LANDASAN TEORI}

\subsection{Wireless Local Area Network (WLAN)}

Wireless LAN (WLAN atau WIFI) adalah sistem transmisi data yang didesain untuk menyediakan akses jaringan yang tidak terbatas tempat atau lokasi antar device komputer dengan menggunakan gelombang radio (Purbo, W.O., 1998).

Spesifikasi 802.11 [IEEE Std 802.11 (ISO/IEC 8802-11: 1999)] adalah standar untuk WLAN yang disahkan oleh Electrical and Electronics Engineers (IEEE) pada tahun 1997. Versi 802.11 ini menyediakan kecepatan transder data 1 Mbps dan 2 Mbps. Versi ini juga menyediakan dasar-dasar metode pensinyalan dan layanan lainnya. Seperti semua standar 802 IEEE, standar 802.11 berfokus pada 2 level model OSI yang paling bawah, yaitu physical layer dan link layer. Aplikasiaplikasi LAN, sistem operasi jaringan, protocol TCP/IP dan Novel NetWare, dapat berjalan pada 802.11-compliant WLAN seperti halnya pada ethernet (Anonime-A, 2006).

68 Febyatmoko, dkk. - Otentikasi, Otorisasi \& Pelaporan Koneksi User Wireless Chillispot \& Server Radius 


\subsection{Chillispot}

Chillispot adalah Wireless Access Point Controller berbasis open source. Chillispot merupakan software Captive Portal yang digunakan untuk otentikasi user Wireless LAN. Cara kerja Chillispot adalah dengan cara meng-capture request halaman web client dan kemudian di-redirect ke halaman web chillispot untuk login otentikasi. Data user dan password yang dimasukkan user akan ditransfer ke server Radius untuk proses otentikasi dan otorisasi hak akses. Apabila data user dan password ter-otentikasi oleh server radius maka user dapat mengakses halaman web di internet (Anonim-C, 2006).

Chillispot dikembangkan pada platform sistem operasi Linux tetapi juga dapat di-compile pada sistem operasi FreeBSD, OpenBSD, Solaris, dan bahkan Apple OSX. Chillispot dikembangkan menggunakan bahasa pemrograman C untuk meningkatkan portabilitas platform sistem operasi yang digunakan.

Untuk membangun hotspot dengan otentikasi, chillispot memerlukan beberapa item:

- Koneksi internet

- Wireless LAN Access Point

- Radius Server

- Database Server

Gambar 1 menggambarkan struktur jaringan hotspot menggunakan chillispot.
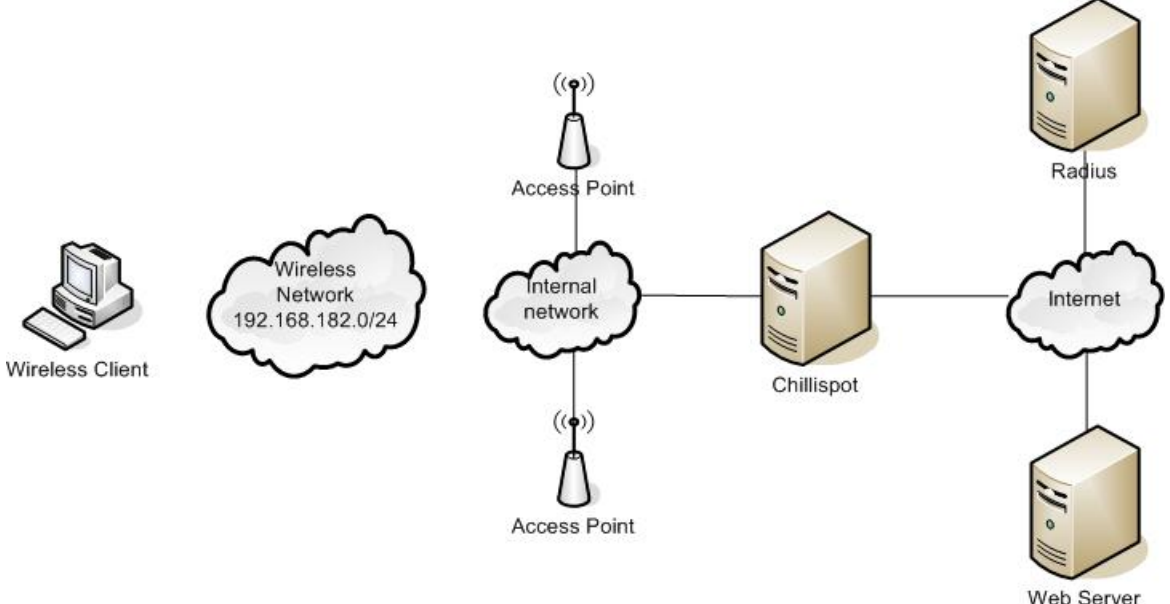

Gambar 1. Struktur jaringan Chillispot

Fitur-fitur yang dimiliki oleh Chillispot antara lain:

1. Server UAM

2. Layanan DHCP

3. Captive Portal 


\subsection{Radius}

Radius adalah singkatan dari Remote Authentication Dial-in User Service yang berfungsi untuk menyediakan mekanisme keamanan dan manajemen user pada jaringan komputer. Radius diterapkan dalam jaringan dengan model client-server.

Server Radius menyediakan mekanisme keamanan dengan menangani otentikasi dan otorisasi koneksi yang dilakukan user. Pada saat komputer client akan menghubungkan diri dengan jaringan maka server Radius akan meminta identitas user (username dan password) untuk kemudian dicocokkan dengan data yang ada dalam database server Radius untuk kemudian ditentukan apakah user diijinkan untuk menggunakan layanan dalam jaringan komputer. Jika proses otentikasi dan otorisasi berhasil maka proses pelaporan dilakukan, yakni dengan mencatat semua aktifitas koneksi user, menghitung durasi waktu dan jumlah transfer data dilakukan oleh user. Proses pelaporan yang dilakukan server Radius bisa dalam bentuk waktu (detik, menit, jam, dll) maupun dalam bentuk besar transfer data (Byte, KByte, Mbyte) (Anonim-B, 2006).

Software server Radius yang digunakan dalam penelitian ini adalah Freeradius yang bersifat modular dan memiliki banyak fitur. Freeradius merupakan software server yang berbasis pada open source dan berlisensi GPL.

\subsection{Analisis Kebutuhan Masukan}

Sistem yang dibangun membutuhkan masukan-masukan sebagai berikut:

1. Data user (model subscriber) yang akan didaftarkan.

2. Data jumlah card dan durasi akses layanan WLAN (model card).

3. Data attribute Radius.

4. Data value attribute Radius.

\subsection{Analisis Kebutuhan Keluaran}

Sistem yang dibangun membutuhkan keluaran-keluaran sebagai berikut:

1. Informasi user (Card dan Subscriber)

Sistem dapat digunakan untuk melihat daftar user (Card dan Subscriber) yang terdaftar.

2. Informasi Card

Sistem menampilkan informasi tentang Card yang telah dibuat, antara lain Card yang tidak terpakai, Card yang sudah terpakai sebagian, dan Card yang sudah habis dipakai. Sistem juga dapat menampilkan catatan akses layanan WLAN (durasi akses dan transfer data) untuk setiap Card.

3. Informasi Subscriber

Sistem menampilkan informasi tentang user yang mendaftar menjadi subscriber. Sistem juga dapat menampilkan catatan akses layanan WLAN (durasi akses dan transfer data) yang dilakukan Subscriber.

\subsection{Kinerja yang harus dipenuhi}

Perangkat lunak yang digunakan untuk mendukung sistem yang akan dibangun diharapkan dapat memenuhi kebutuhan-kebutuhan antara lain: 
1. Mampu menangani otentikasi user (Card dan Subscriber).

2. Mampu melakukan otorisasi layanan pada user yang berhasil diotentikasi.

3. Mampu menyimpan dan memberikan hasil penghitungan durasi akses dan data transfer pada koneksi user yang terjadi.

\section{PERANCANGAN SISTEM}

Sistem Otentikasi, Otorisasi, dan Pelaporan menggunakan radius server ini dapat digambarkan dengan arsitektur desain sistem berorientasi objek menggunakan UML (Unified Modelling Language).

1. User

Entitas luar pada sistem ini adalah:

User adalah user yang menggunakan layanan dalam jaringan komputer wireless.

2. Administrator Jaringan

Adalah Administrator pada jaringan yang mengelola server radius, memonitor dan mengontrol kinerja server radius.

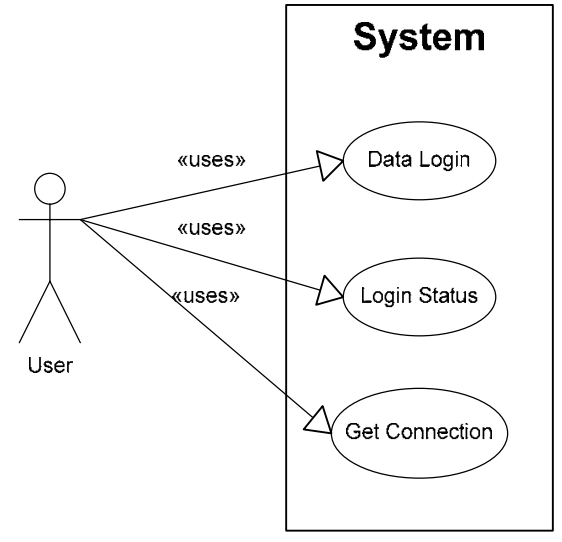

Gambar 2. Use Case Diagram User

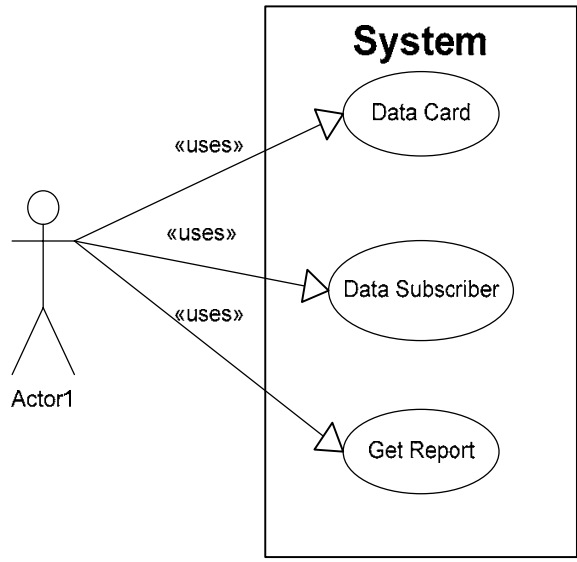

Gambar 3. Use Case Diagram Administrator

\subsection{Activity Diagram}

Activity diagram menggambarkan berbagai alir aktifitas dalam aplikasi yang sedang di rancang, bagaimana masing masing alir berawal, keputusan yang mungkin terjadi dan bagaimana mereka berakhir. 


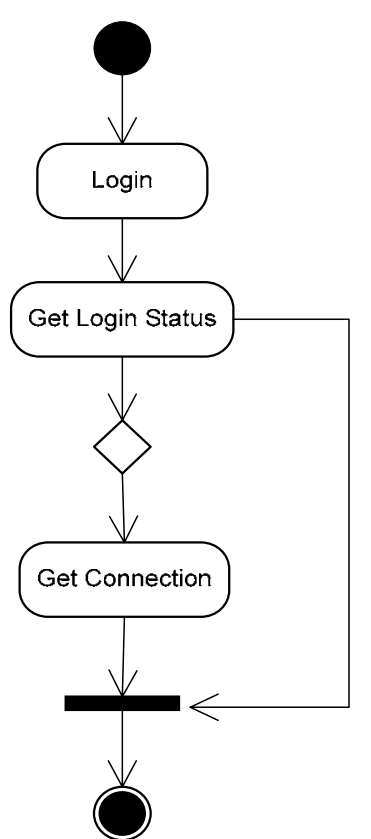

Gambar 4. User Activity Diagram

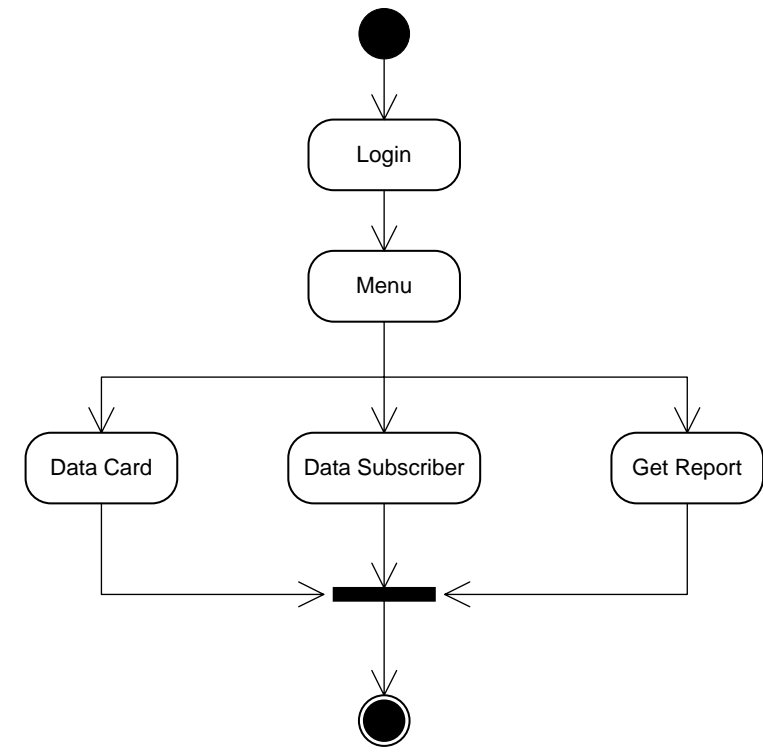

Gambar 5. Administrator Activity Diagram

\subsection{Peta web}

Untuk membangun antarmuka dibutuhkan peta web seperti pada Gambar 6.

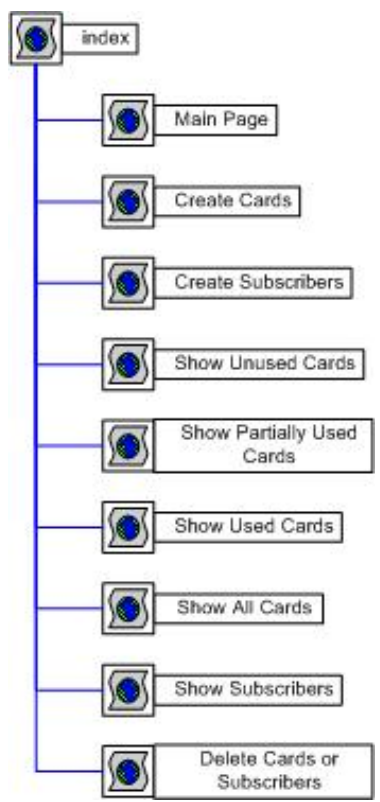

Gambar 6. Peta web

72 Febyatmoko, dkk. - Otentikasi, Otorisasi \& Pelaporan Koneksi User Wireless Chillispot \& Server Radius 


\subsection{Asumsi yang dipakai}

Dalam tahap implementasi digunakan asumsi-asumsi sebagai berikut:

1. Komputer yang dikonfigurasi sebagai server radius sekaligus gateway menggunakan sistem operasi Linux Fedora Core 4.

2. Sistem operasi komputer pada client bersifat multi platform.

3. Access Point yang digunakan dalam penelitian ini adalah Linksys WAP 54G

4. Jaringan lokal Wireless LAN yaitu 192.168.100.0/24.

5. Server dikonfigurasi dengan 2 (dua) alamat IP 192.168.100.250 untuk interface jaringan eksternal dan alamat IP 192.168.182.1 untuk interface WLAN.

6. Alamat IP DNS server untuk WLAN 202.150.76.202 dan alamat ip gateway WLAN 192.168.182.1.

7. Seluruh Aplikasi Pendukung yang digunakan kecuali untuk developing (DreamWeaver dan Zend Studio) adalah Aplikasi Free dan Open Source.

8. Aplikasi dan versi yang dipakai sebagai berikut : Apache-2.0.59, PHP-4.1.10

9. File-file aplikasi PHP diletakkan di / var/www/html/phpmyprepaid

10. Nama Database yang digunakan adalah "radius", nama user database adalah "root" dengan password " $\mathrm{q}$ ".

Secara garis besar implementasi sistem sebagai berikut:

1. Mengkonfigurasi komputer sebagai server Radius.

2. Mengkonfigurasi komputer sebagai server UAM.

3. Membangun Web Server dengan fasilitas SSL dan PHP untuk antarmuka aplikasi administrasi.

4. Membangun Database Server.

5. Mengkonfigurasi Access Point.

6. Mengkonfigurasi komputer client agar terkoneksi dengan server Radius dan server UAM.

7. Membangun Aplikasi Administrasi yang berfungsi untuk pengaturan sistem.

\section{IMPLEMENTASI RANCANGAN}

\subsection{Login aplikasi administrasi}

Login aplikasi administrasi menggunakan fasilitas yang disediakan server web Apache, menggunakan file .htacess dan .htpasswd. Gambar login aplikasi administrasi dapat dilihat pada Gambar 7.

\subsection{Preview keseluruhan}

Gambar 8 menampilkan web secara keseluruhan. 


\subsection{Create Timed Cards}

Gambar 9 menampilkan form yang digunakan administrator untuk membuat Card yang terdiri dari Username dan Password digunakan untuk otentikasi.

\subsection{Create New Subscribers} baru.

Gambar 10 menampilkan form yang digunakan untuk membuat Subscribers

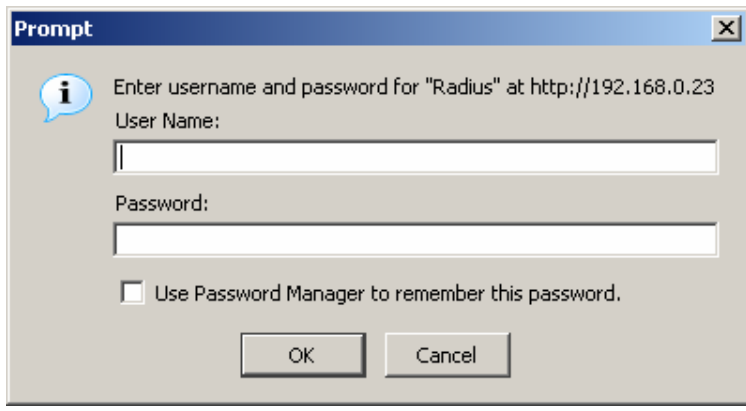

Gambar 7. Login aplikasi administrasi

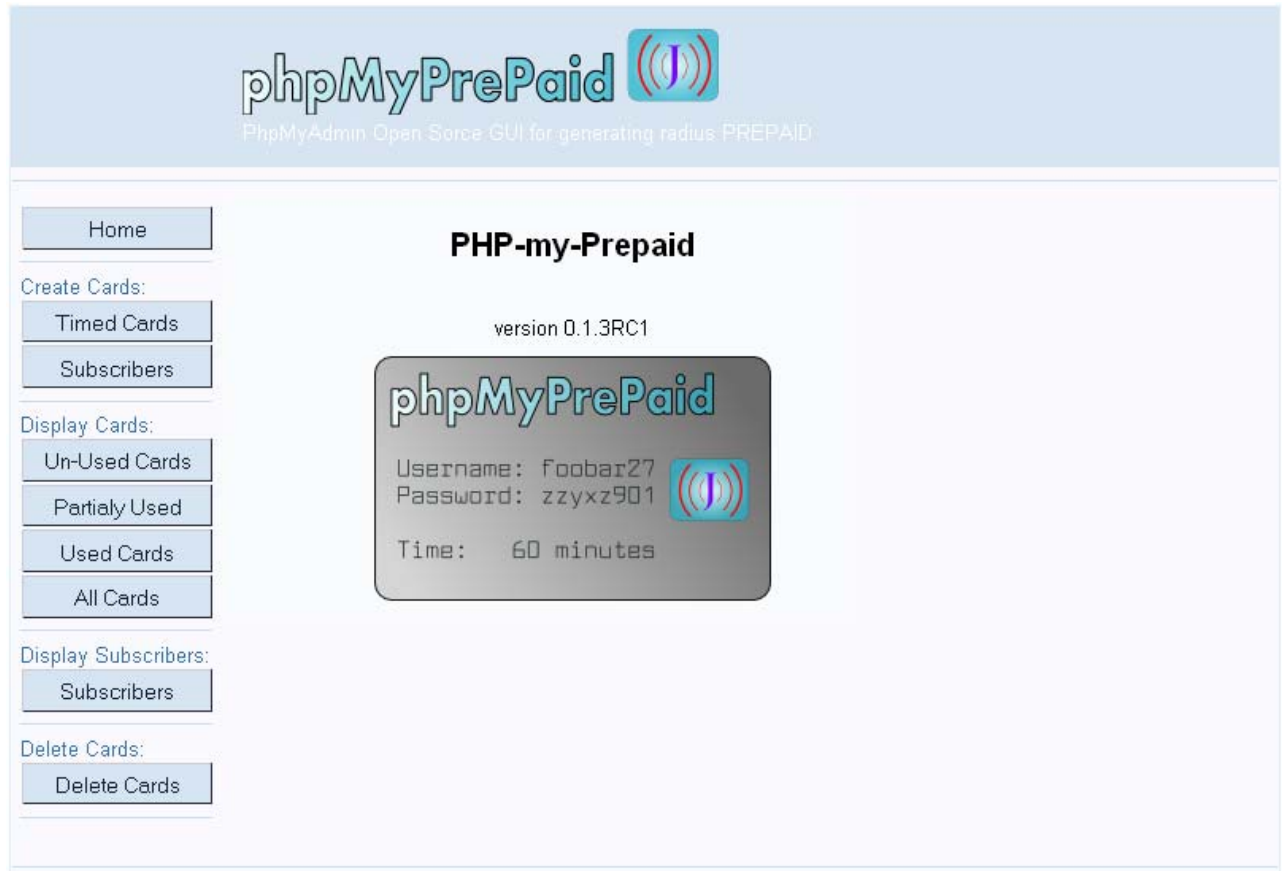

Gambar 8. Preview Web

74 Febyatmoko, dkk. - Otentikasi, Otorisasi \& Pelaporan Koneksi User Wireless Chillispot E Server Radius 


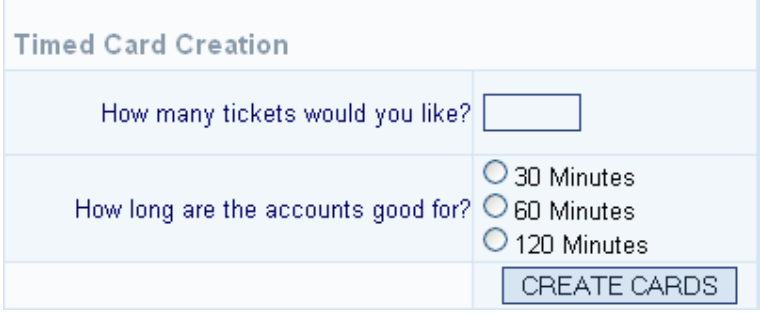

Gambar 9. Create New Cards

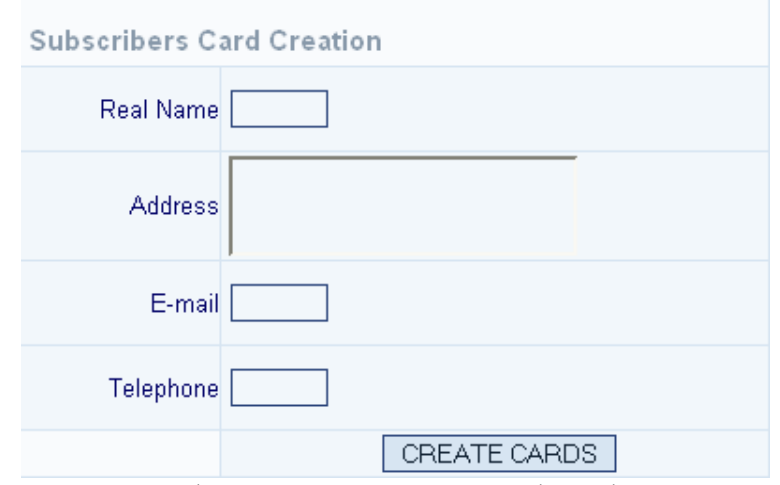

Gambar 10. Create New Subscribers

\subsection{Show Unused Cards}

Gambar 11 menampilkan Card yang belum/tidak terpakai.

All Unused Accounts

\begin{tabular}{l|l|}
\hline \multicolumn{1}{c}{ Sort by Name } & Purchased \\
\cline { 2 - 2 } cadkuk11 & 120 Min \\
mulneb10 & 120 Min \\
pucpir5 & 30 Min \\
sebpog14 & 60 Min \\
sortap9 & $120 \mathrm{Min}$
\end{tabular}

Showing results 1 to 5 of 5

Gambar 11. Show Unused Cards

\subsection{Show Partially Cards}

Gambar 12 dan 13 menampilkan Card yang sudah terpakai sebagian (interval waktu terpakai sebagian. 
All Partialy Used Accounts

\begin{tabular}{|c|c|c|} 
Sort by Name & Value & Used \\
\cline { 1 - 1 } noctut14 & 30 Min & 3 Min \\
\hline pinded14 & 60 Min 1 Min \\
\hline
\end{tabular}

Showing results 1 to 1 of 1

Gambar 12. Show Partially Cards

\begin{tabular}{|c|c|c|} 
Sort by Name & Value & Used \\
\cline { 1 - 2 } \cline { 1 - 1 } pinded14 & 60 Min & 1 Min \\
\cline { 1 - 2 } noctut14 & 30 Min & 6 Min \\
\hline
\end{tabular}

Showing results 1 to 1 of 1

\begin{tabular}{|c|c|c|c|c|c|}
\hline \multicolumn{6}{|c|}{ noctut14 Username Cards Log } \\
\hline Session Start & Session Stop & Time & Reason & Download Kb & Upload Kb \\
\hline 2006-04-12 18:44:14 & $2006-04-12$ 18:47:15 & 3 Min & User-Request & 11 & 25 \\
\hline 2006-04-12 18:50:28 & 2006-04-12 18:53:11 & 3 Min & User-Request & 105 & 1645 \\
\hline
\end{tabular}

Gambar 13. Show Partially Card and Activities

\subsection{Show Used Cards} terpakai.

Gambar 14 menampilkan Card yang durasi waktu aksesnya sudah habis

$$
\text { All Used Accounts }
$$

\begin{tabular}{|c|c|c|}
\hline Sort by Name & Value & Used \\
\cline { 1 - 1 } noctut14 & 30 Min & 30 Min \\
\hline
\end{tabular}

Showing results 1 to 1 of 1

\begin{tabular}{|l|l|l|l|l|l|}
\hline \multicolumn{7}{|c|}{ noctut14 Username Cards Log } \\
\hline Session Start & Session Stop & Time & Reason & Download Kb & Upload Kb \\
\hline $2006-04-12 ~ 18: 44: 14$ & $2006-04-12 ~ 18: 47: 15$ & 3 Min & User-Request & 11 & 25 \\
\hline $2006-04-12 ~ 18: 50: 28$ & $2006-04-12 ~ 18: 53: 11$ & 3 Min & User-Request & 105 & 1645 \\
\hline $2006-04-12 ~ 18: 56: 39$ & $2006-04-12 ~ 19: 20: 56$ & 24 Min & Session-Timeout & 201 & 1857 \\
\hline
\end{tabular}

Gambar 14. Show used Cards

\subsection{Show All Cards}

Gambar 15 menampilkan informasi tentang semua Card yang sudah dibuat.

76 Febyatmoko, dkk. - Otentikasi, Otorisasi \& Pelaporan Koneksi User Wireless Chillispot E Server Radius 


\begin{tabular}{|l||l||l||l|}
\hline \multicolumn{1}{|c|}{ Username } & Purchased & Total Use & \multicolumn{1}{c|}{ Created } \\
\cline { 4 - 5 } cadkuk11 & 120 & 0 & $\begin{array}{l}2006-04-12 \\
06: 41: 01\end{array}$ \\
\hline mulneb10 & 120 & 0 & $\begin{array}{l}2006-04-12 \\
06: 41: 01\end{array}$ \\
\hline noctut14 & 30 & 0 & $\begin{array}{l}2006-04-12 \\
06: 43: 55\end{array}$ \\
\hline pinded14 & 60 & 1 & $\begin{array}{l}2006-04-12 \\
06: 42: 12\end{array}$ \\
\hline pucpir5 & 30 & 0 & $\begin{array}{l}2006-04-12 \\
06: 34: 10\end{array}$ \\
\hline sebpog14 & 60 & 0 & $\begin{array}{l}2006-04-12 \\
06: 40: 56\end{array}$ \\
\hline sortap9 & 120 & 0 & $\begin{array}{l}2006-04-12 \\
06: 41: 01\end{array}$ \\
\hline
\end{tabular}

Showing results 1 to 7 of 7

Gambar 15. Show All Cards

\subsection{Show Subscribers} sistem.

Gambar 16 menampilkan informasi tentang subsciber yang terdaftar dalam

All Subscribers listed in the Database

\begin{tabular}{|c|c|c|c|}
\hline Username & realname & created & expire \\
\hline ladtal13 & gesit & $\begin{array}{l}2006-04-12 \\
07: 33: 05\end{array}$ & $\begin{array}{l}\text { 12 May } 2006 \\
07: 33: 05\end{array}$ \\
\hline pipkut15 & sofyan & $\begin{array}{l}2006-04-12 \\
07: 34: 04\end{array}$ & $\begin{array}{l}\text { 12 May } 2006 \\
07: 34: 04\end{array}$ \\
\hline
\end{tabular}

Showing results 1 to 2 of 2

\begin{tabular}{|c|c|c|c|c|c|}
\hline \multicolumn{6}{|c|}{ ladtal13 User Log } \\
\hline Session Start & Session Stop & Time & Reason & Download Kb & Upload Kb \\
\hline $2006-04-12$ 19:36:4 & 3 2006-04-12 19:38:17 & $2 \mathrm{Min}$ & User-Request & 66 & 2547 \\
\hline 2006-04-12 19:38:3 & 1 2006-04-12 19:38:48 & $0 \mathrm{Min}$ & User-Request & & 4 \\
\hline
\end{tabular}

Gambar 16. Show Subscribers

\subsection{Delete Cards and Subscribers}

Gambar 17 digunakan untuk menghapus data Card atau Subscriber yang terdaftar dalam sistem. 


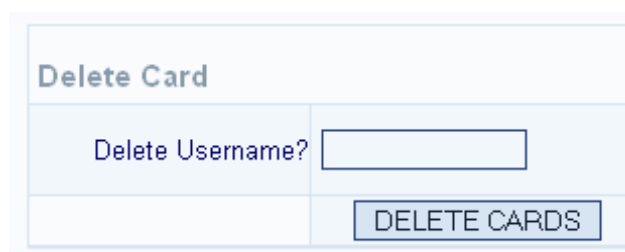

Gambar 17. Delete Cards atau Subscribers

\section{SIMPULAN}

Setelah dilakukan pengujian dapat ditarik kesimpulan sebagai berikut:

1. Penerapan sistem otentikasi dan otorisasi koneksi user dengan menggunakan Chillispot dan server Radius memberikan level keamanan jaringan komputer wireless yang lebih baik. User yang dapat menggunakan layanan jaringan harus terdaftar dalam sistem sehingga tidak semua orang dapat menggunakan layanan jaringan.

2. Dengan mekanisme pelaporan detail tentang koneksi yang dilakukan user, memudahkan administrator dalam memonitor penggunaan layanan jaringan dan dapat dijadikan dasar bagi pengembangan aplikasi billing yang dapat diterapkan pada institusi komersial seperti Penyedia Jasa Internet.

3. Aplikasi administrasi server Radius yang dikembangkan memudahkan administrator dalam mengelola sistem.

\section{SARAN} berikut:

Beberapa saran untuk pengembangan dan penelitian selanjutnya sebagai

1. Spesifikasi komputer yang digunakan untuk pengembangan dan implementasi terlalu rendah, diharapkan nantinya jika ada penelitian sejenis menggunakan spesifikasi komputer yang lebih baik.

2. Belum ada sistem billing yang bisa dikembangkan untuk institusi komersial.

3. Fitur-fitur yang disediakan dalam paket Chillispot dan Freeradius belum diekplorasi sepenuhnya, diharapkan pada penelitian selanjutnya, fitur-fitur tersebut diekplorasi.

4. Aplikasi administrasi server Radius yang dikembangkan belum mampu mengelola sistem server Radius secara keseluruhan.

5. Kepada para pengembang dapat memberikan masukan dan sekaligus melakukan developing langsung ke sistem ini.

\section{PUSTAKA}

Anonim-A. (2006). 802.1x Port Based Network Authentication, http://www.tldp.org/ HOWTO/8021X-HOWTO/, diakses tanggal 14 Januari 2006.

Anonim-B. (2006). GNU Radius Reference Manual, http://www.gnu.org/software/ radius/manual/index.html, diakses tanggal 14 Januari 2006. 
Anonim-C. (2006). Chillispot Forum, http://www.chillispot.org/forum/, diakses tanggal 20 Februari 2006.

Anonim-D. (2006). Swarm Internet Hotspots Forum, http://topup.ie/phpBB2/, diakses tanggal 20 Februari 2006.

Anonim-E. (2006). Freeradius Mail Archives, http://www.mailarchive.com/freeradius-users@lists.freeradius.org/, diakses tanggal 20 Februari 2006.

Jansen, M., Merz, A. (2005). PEAR Manual, America: The PEAR Documentation Group.

Prasetyo, D.D. (2003). Tip dan Trik Kolaborasi PHP dan MySQL Untuk Membuat Web Database yang Interaktif, Jakarta: Elex Media Komputindo.

Purbo, W.O. (1998). TCP/IP Standar, Desain, dan Implementasi. Jakarta: PT Elek Media Komputindo.

Sean, Bracken. How To Setup WI-FI Hotspot, http://howtoforge.com/ wifi_hotspot_setup, diakses tanggal 20 Februari 2006. 